\title{
PENSAR O PASSADO, NARRAR A HISTÓRIA DOS AFRODESCENDENTES NA BAHIA: UM E-BOOK SOBRE MARIA FELIPA DE OLIVEIRA NO ENSINO FUNDAMENTAL
}

\author{
Carlos Eduardo Gomes Nascimento (UFBA) ${ }^{1}$
}

\begin{abstract}
RESUMO: O artigo apresenta o projeto "Mídias digitais para pensar o passado e narrar a história dos afrodescendentes na Bahia", que considerou a problemática: O e-book pode ser um recurso educativo de preservação da memória histórica dos afrodescendentes na Bahia? Ressalta a relação entre mídias digitais na escola e a constituição histórica étnico-racial, a fim de estabelecer um sentimento de pertença dos alunos à história e a cultura afrodescendente. Para tanto, contou-se a história de Maria Felipa de Oliveira, mulher negra e heroína da Independência do Brasil na Bahia e propôs-se a recontagem dessa história pelos alunos, com a produção de um e-book. Observou-se que as mídias digitais podem aproximar os alunos da história dos afrodescendentes, significando o passado, criando o futuro.
\end{abstract}

PALAVRAS-CHAVE: História dos afrodescendentes. Cultura Digital. Educação.

ABSTRACT: The article presents the project "Digital media to think about the past and tell the story of Afro-descendants in Bahia", which considered the problem: Can the e-book be an educational resource to preserve the historical memory of Afro-descendants in Bahia? It highlights the relationship between digital media in school and the historical ethnic racial constitution, in order to establish a sense of belonging of students to the history of Afrodescendant culture. For that, the story of Maria Felipa de Oliveira, a black woman and heroine of the Independence of Brazil in Bahia, was recounted, and the story was recounted by the students, with the production of an e-book. It was observed that digital media can bring students closer to the history of Afro-descendants, meaning the past, creating the future.

KEYWORDS: History of Afrodescendants. Digital Culture. Education.

\section{INTRODUÇÃO}

Este artigo apresenta a produção de um e-book na plataforma on-line LivrosDigitais.org, realizada pelo professor com os alunos do $4^{\circ}$ ano do Ensino Fundamental, em uma escola municipal de Salvador, realizada por meio do projeto "Mídias digitais para pensar o passado e narrar a história dos afrodescendentes na Bahia". A aproximação da educação com os recursos tecnológicos objetiva estabelecer relações entre a produção e divulgação on-line de mídias digitais; a história da formação da população afrodescendente brasileira e a aprendizagem da leitura e da escrita, por meio da produção de uma mídia educacional, um e-book, disponibilizado em uma plataforma on-line. A construção e publicação do e-book, na plataforma on-line LivrosDigitais.org, foi realizada através da mediação do professor e da efetiva participação dos estudantes de Ensino Fundamental, crianças que estão estabelecendo relações com o mundo da tecnologia, da leitura, da escrita e da história.

A educação marca o encontro entre as gerações: as crianças e os jovens encontramse com gerações mais velhas e trocam saberes, conhecimentos, experiências. A aprendizagem das crianças e dos jovens não ocorre apenas na escola, mas também na família, na comunidade e, atualmente, através dos meios midiáticos na internet: redes sociais, e-books, blogs, memes,

\footnotetext{
${ }^{1}$ Mestre em Educação pela Universidade Federal da Bahia (UFBA). E-mail: carlos_gomes02@hotmail.com
} 
games, séries e demais narrativas on-line. Nesse processo formativo, as crianças e os jovens podem aprender sobre sua própria história e encontrar o seu lugar no mundo simbólico e cultural, por meio da troca de saberes com as gerações mais antigas, conhecendo o passado histórico. As diversas possibilidades de aprender permitem que os jovens e as crianças criem laços de pertencimento com esse mundo e suas histórias. Conforme aponta o educador Pedro Demo (2009):

\begin{abstract}
De um lado, estão crenças arcaicas que imaginam aprendizagem como simples instrução feita sempre dentro de cânones fixos, em particular na relação hierárquica, disciplinar, professor/aluno. De outro, estão novos ventos, muito impulsionados por novas tecnologias, que, ao revelarem novas dinâmicas (por exemplo, mais centradas nos alunos e que valorizam igualmente modos informais de aprender), preferem formatos mais flexíveis, participativos, coletivos de aprender, já que a razão de tudo é aprender bem (DEMO, 2009, p. 62).
\end{abstract}

As transformações nos modos de aprender favorecidas pelo acesso à internet e às mídias on-line constituem-se no fenômeno da cibercultura (LEVY, 1999). O fenômeno da cibercultura atravessa também as práticas educativas possibilitando novas interações na aprendizagem entre os alunos e os textos, ampliando a capacidade leitora e a produção e divulgação on-line de seus escritos, vídeos, podcasts e outros recursos visuais. Com as novas tecnologias, as relações entre sujeitos em ambientes on-line rompem as barreiras geográficas, favorecem novas formas de se apropriar da leitura e da escrita, criando possibilidades para o desenvolvimento de práticas educacionais mais dinâmicas, ultrapassando os muros da escola tradicional. O professor e pesquisador André Lemos ao analisar o fenômeno da cibercultura expressa que:

\footnotetext{
O leitor é editor e distribuidor. Nova forma de leitura onde a ação de edição e compartilhamento pode ser feita pelo leitor. Cresce formas e instrumentos de uma cultura letrada que se faz por uma leitura sociabilizada. O leitor é também "tipógrafo" ("Desafios da Escrita" de R. Chartier) que pode mexer nas fontes e alterar as localizações das informações. Só há textos e leitores móveis (LEMOS, 2011).
}

O sentido de pertença à herança cultural letrada que as crianças e jovens estabelecem com o mundo vem se transformando, com a popularização do acesso à internet. Conforme destacam John Palfrey e Urs Gasser (2011, p. 29): "A era da internet, em que estão crescendo os Nativos Digitais, está proporcionando outra grande mudança no que significa construir e administrar a própria identidade". Neste contexto, torna-se fundamental tanto para as famílias, quanto para as escolas refletirem e debaterem de que maneira as crianças podem usar a internet como recurso de aprendizagem, através do contato com as diversas narrativas e recursos on-line. Aos educadores cabe refletir que a educação ultrapassa os muros da escola e das Universidades, para ganhar dimensões do mundo digital. Assim, na interação com as mídias on-line, as crianças e os jovens experimentam novas formas de constituição de identidades.

[...] a formação da identidade entre os Nativos Digitais é diferente da formação da identidade entre as gerações pré-digitais, no sentido de que há mais experimentação e reinvenção das identidades, e diferentes modos de expressão, como o YouTube e os blogs. Esses modos de expressar a identidade muitas vezes parecem aos pais e professores mais estranhos do que realmente são (PALFREY; GASSER, 2011, p. 30). 
Embora inseridas na cultura digital, as crianças ainda não conseguem sozinhas se apropriar das diversas potencialidades que a tecnologia pode favorecer na construção de sua identidade. Considerando que a criança se apresenta em fase de desenvolvimento de suas capacidades cognitivas, afetivas e emocionais, é necessária a mediação do professor na relação entre o processo de aprendizagem da criança e o mundo digital. O professor deve orientar e debater com as crianças acerca da existência do preconceito e da violência viralizadas na internet como o bullying, a homofobia e o racismo. Nesse contexto, é imprescindível pensar práticas educativas também em ambientes on-line contra essas formas de violência e suas implicações sociais, pois a educação favorece a reflexão e a conscientização. No caso do racismo, que se faz presente de forma estrutural na sociedade brasileira, também se apresenta na internet. De acordo com Berleze e Pereira (2017, p. 12): “o racismo é forte nas redes sociais, desmistificando a ideia de democracia racial e evidenciando que o preconceito real, vivido pelos negros no seu dia a dia, que os impede, em muitos casos, de ter acesso a oportunidades econômicas e sociais, viraliza no mundo virtual". Considerando essa perspectiva, a presente intervenção didática aborda a importância da construção da identidade étnica e racial, de crianças, alunas e alunos do ensino fundamental a partir da história e cultura afro-brasileira na Bahia, em especial.

Ancorada em uma proposta de produção educativa on-line, mediada por atividade docente, produziu-se uma prática educacional que objetivou favorecer o debate racial com as crianças do ensino fundamental, através da produção e divulgação on-line de uma mídia digital. A mídia escolhida foi um e-book, por favorecer a interação dos alunos com um recurso digital, a produção, edição e divulgação de experiências de leitura e escrita on-line e a compreensão da identidade étnico-racial brasileira. Para isso, o e-book foi escrito pelos alunos, editado pelo professor na plataforma on-line LivrosDigitais.org. Desta maneira, criaram-se novos debates, novas relações de pertencimento dos estudantes com a história, além de favorecer a aprendizagem da leitura e da escrita e a interação on-line com outros leitores. De acordo com Valletta (2014):

\begin{abstract}
Entende-se que a alfabetização/competência digital é um processo que se encontra num momento o qual educandos e educadores aprendem ao mesmo tempo. A escola, com isso, passa a ser uma dentre tantas outras fontes/ambientes de produção e divulgação de informações. [...] Essa função será eficaz na medida em que a escola, e educadores aprendam a fazer uso das Tecnologias Digitais (TD) como uma ferramenta didática (VALLETTA, 2014, p. 2).
\end{abstract}

A proposta didática almeja inspirar professores na criação de práticas pedagógicas entre as tecnologias e a educação, através da produção de uma mídia on-line, estabelecendo laços entre alunos, professores e sociedade com a história das identidades étnica e racial, a partir da cultura afro-brasileira.

A aproximação da educação com os recursos tecnológicos digitais objetiva estabelecer relações entre a produção e divulgação on-line de mídias digitais, tomando por base as pesquisas desenvolvidas por Levy (1996; 1999); Demo (2009); Palfrey e Gasser (2011); Lemos (2011); Serres (2013); Nicolau (2014); Valletta (2014) e Pereira (2017), Rocha (2018), dentre outros. A produção coletiva de uma mídia on-line com os alunos do ensino fundamental tem como referência a concepção de interação pedagógica de Vygotsky (2001) a qual propõe que alunos possam aprender juntos, de forma dialógica e participativa. O projeto fundamentou-se também nos seguintes livros: "llê Ifé. O Sonho do laô Afonjá" de Vanda Machado e Carlos 
Petrovich (2002) e "Maria Felipa de Oliveira. Heroína da Independência da Bahia" de Eny Kleyde Vasconcelos Farias (2010), sobre a aprendizagem da cultura afro-brasileira e a educação.

\title{
EDUCAÇÃO, CULTURA DIGITAL E E-BOOK
}

Educação é um ato político, como afirmava Paulo Freire (1991). A escola é um ambiente formativo de inter-relações entre os sujeitos e os saberes que permeiam o mundo. Como lembra Lev Vygotsky (1991, p. 22): "O ser humano só adquire cultura, linguagem, desenvolve o raciocínio se estiver inserido no meio com os outros. A criança só vai se desenvolver historicamente se inserida no meio social". Em meio a esse contexto formativo, político e social, atualmente, surge o fenômeno tecnológico da cultura digital que através das mídias on-line cria múltiplas potencialidades na educação. Como destaca Fonseca (2013, p. 3):

\begin{abstract}
Em se tratando de tecnologia, o potencial não reside nela própria, e sim na interação com o homem. Por isso, para que os experimentos pedagógicos alcancem seus objetivos, é preciso que os envolvidos, nesse caso, alunos e professores, estejam preparados e dispostos, para que essa apropriação possa de fato representar transformação e gerar ganhos para a Educação.
\end{abstract}

Desse modo, a apropriação da tecnologia pelos professores e estudantes pode constituir um conhecimento do mundo em que se vive, das outras formas de pensar, das novas maneiras de nos relacionarmos com os outros, das desigualdades e injustiças que ainda permeiam essas relações. Desta maneira, a produção de uma mídia articulada com a aprendizagem de conteúdo, conhecimentos e saberes escolares torna-se um exercício importante para educar.

As mídias e as tecnologias de informação e comunicação proporcionam à comunidade escolar, alunos, professores e pais, novas maneiras de aprender a se relacionar com a cultura e a sociedade. Frente a esse contexto, o filósofo francês Michel Serres, na obra A Polegarzinha (2013), analisou as implicações das tecnologias digitais e da mídia on-line na educação das crianças. Serres (2013) lembra que observou "pequenos estudantes enviarem SMS com os polegares mais rápidos que eu jamais conseguiria com todos os meus dedos entorpecidos, os batizei de a Polegarzinha e o Polergazinho". Segundo Serres (2013):

\begin{abstract}
Essas crianças, então, habitam o virtual. As ciências cognitivas mostram que o uso da internet, a leitura ou a escrita de mensagens com o polegar, a consulta à Wikipédia ou ao Facebook não ativam os mesmos neurônios nem as mesmas zonas corticais que o uso do livro, do quadro-negro ou do caderno. Essas crianças podem manipular várias informações ao mesmo tempo (SERRES, 2013, p. 19).
\end{abstract}

Os estudantes, uma geração diferente dos pais e de alguns professores, assumem maior protagonismo na criação de novas formas de comunicar, escrever, ler e se relacionar com o conhecimento. Os recursos tecnológicos pelas mídias on-line deixaram de ser uma promessa sobre o processo de ensino e aprendizagem nas escolas.

Conforme Nicolau e Nicolau (2014, p. 1):

$\mathrm{Na}$ medida em que a tecnologia do digital foi desenvolvendo-se e estabelecendo, no âmbito da cibercultura, um novo padrão de interações sociais, a área da educação passou a se mover, quase que por completa, em direção a essa promissora vertente de construção de conhecimentos que se instaurou na sociedade da informação. 


\section{$=$ TRAMA $=$}

O fenômeno da cibercultura, segundo pensador francês Pierre Levy (1999, p. 17), é "conjunto de técnicas (materiais e intelectuais), de práticas, de atitudes, de modos de pensamentos e de valores que se desenvolvem juntamente com o ciberespaço". Esse desafio lançado pela cibercultura nos ambientes digitais chegou aos educadores não para se tornarem especialistas e técnicos nas tecnologias e mídias, mas para descobrir potencialidades pedagógicas, na construção de recursos didáticos para a criação, interação e aprendizagem na sala de aula com o conhecimento. Em meio a esse desafio de desconstruir antigas formas de organização e distribuição do conhecimento nas escolas, educar também implica no trabalho com as tecnologias digitais e mídias on-line.

A cultura digital modificou a relação entre a educação e o conhecimento. O conhecimento está explicado e documentado na Web, sem maiores erros do que as velhas enciclopédias. Aquele conhecimento transmitido de uma maneira tradicionalista e bancária por alguns professores, atualmente encontra-se à disposição em ambientes virtuais que proporcionam a aprendizagem como sites, blogs, vídeos, redes sociais, podcast, e-books, etc.

O e-book constitui-se no formato digital dos livros físicos, acessível em rede, pode ser lido e compartilhado on-line e através dos mais diversos dispositivos digitais. Para Procópio (2010), a leitura de um livro digital, compõe-se através de três constituintes: o hardware utilizado (notebook, tablet, smatphone, etc); o reader, software de leitura do livro; e o e-book, o conteúdo. A leitura em tela apresenta-se como uma pequena janela da qual o leitor explora diversas potencialidades. Com o e-book a experiência da leitura modificou-se, segundo Levy:

\footnotetext{
O suporte digital apresenta uma diferença considerável em relação aos hipertextos anteriores à informática: a pesquisa nos índices, o uso dos instrumentos de orientação, de passagem de um nó a outro, fazem-se nele com grande rapidez, da ordem de segundos. Por outro lado, a digitalização permite associar na mesma mídia e mixar finalmente os sons, as imagens animadas e os textos. Segundo essa primeira abordagem, o hipertexto digital seria, portanto, definido como uma coleção de informações multimodais disposta em rede para a navegação rápida e 'intuitiva' (LEVY, 1996, p.44).
}

Com efeito, o e-book constitui-se enquanto um recurso didático-pedagógico que explora a complexidade do processo de ensinar e de aprender (NICOLAU, 2014a). Dessa maneira, implementar novas tecnologias na sala de aula torna-se fundamental na transformação das estruturas da educação e configuração no aprendizado escolar para os estudantes do século XXI.

\section{E-BOOK E A TEMÁTICA ÉTNICO-RACIAL NA ESCOLA}

Para o desenvolvimento do projeto didático "Mídias digitais para pensar o passado e narrar a história dos afrodescendentes na Bahia" optou-se pela produção do e-book como um recurso educativo. O e-book expressa a dinamicidade na aprendizagem mais significativa para as crianças que estão imersas em mundo digital e tecnológico, mas que ainda não compreendem as implicações formativas das mídias on-line. Elaborar e editar um e-book junto com os alunos do ensino fundamental requer sociabilidade, comunicação e interação constante entre os sujeitos, professor, alunos e coordenadora pedagógica. Embora parte dos alunos possuam acesso aos recursos digitais e a internet, a produção de e-book como recurso educacional se mostrou como algo novo para eles, ampliando as possibilidades de construção de habilidades, competências e estreitamento de laços durante a realização da atividade.

Mesmo com a inclusão da temática "História e Cultura Afro-Brasileira" nos currículos oficiais, através da Lei n 10.639/2003 e da Lei n 11. 645/2008, ainda é fundamental refletir 
sobre as práticas didáticas que envolvem a cultura e a história afro-brasileira no cotidiano da escola. Conforme as Orientações e Ações para a Educação das Relações Étnico-Raciais: "Reconhecer as diferenças é um passo fundamental para a promoção da igualdade, sem a qual a diferença poderá vir a se transformar em desigualdade" (BRASIL, 2006, p. 32,). Acerca da população negra na cidade de Salvador, questiona Vanda Machado (2002, p. 109): "Em Salvador somos mais de $80 \%$ negros. Entretanto a escola como instituição que representa os valores civilizatórios, tende a firmar apenas valores da sociedade que se porta como branca e eurocêntrica. É hora de reparar".

Os conflitos humanos presentes na sociedade são vivenciados pelas crianças na escola, nas redes sociais e precisam ser discutidos, mediados pelos adultos. Nas interações on-line das redes sociais difundem-se mais rapidamente os efeitos desses conflitos.

\begin{abstract}
A interação mútua que os atores sociais estabelecem são eventos localizados num tempo e espaço, ficam armazenados junto das novas interações que surgirão na sequência. Se alguém recebeu uma mensagem ofensiva em alguma comunidade o conflito gerado naquele texto vai possibilitar novos eventos comunicativos. Mesmo que o autor das mensagens peça desculpas, novas comunicações vão ocorrer na sequência de outras mensagens. Isso permite que se mude o evento anterior, mas não eliminá-lo da sequência, da historicidade interativa, isto é, pode-se tentar ressignificar os atos anteriores, mas não mudá-los, tendo em vista a progressão temporal do processo (ROCHA, 2018, p. 234).
\end{abstract}

Através de interações dialógicas que privilegiem a diversidade, garante-se o relacionamento plural na escola e nos ambientes virtuais. Conforme lembra Vanda Machado (2002, p. 111): "O reconhecimento da nossa multietnicidade com a maioria negra, muitas vezes se coloca na contramão da construção do conhecimento, para as crianças afrodescendentes. A escola precisa aproximar-se da cultura afro-brasileira". Desta maneira, a questão da cultura afro-brasileira deve ser discutida e abordada na escola, promovendo uma educação transformadora que crie novas formas de ser e pensar o mundo.

A produção do e-book visa recontar a história de Maria Felipa de Oliveira, mulher negra, que participou da guerra da Independência do Brasil na Bahia, em 1823. Maria Felipa de Oliveira foi declarada Heroína da Pátria Brasileira pela Lei Federal no 13.697, em 26 de julho de 2018², tendo seu nome inscrito no "Livro dos Heróis e Heroínas da Pátria". Conta-se que, durante as batalhas para Independência do Brasil, Maria Felipa, uma mulher negra liderou, na Ilha de Itaparica na Bahia, um grupo de homens e mulheres, queimando mais de 40 embarcações portuguesas que estavam em assalto na Baía de Todos os Santos. A história de Maria Felipa de Oliveira apresenta-se enquanto memória e patrimônio, destacando-a no contexto históricosimbólico das lutas que participou. Conforme destaca Eny Farias (2010, p. 53):

Endente-se que a história brasileira deve ser submetida também a novos processos historiográficos para ser reelaborada e reescrita de forma crítica e cidadã. É dentro deste modo de pensar que se tenta escrever sobre Maria Felipa de Oliveira. É relevante afirmar que o sujeito deve ser educado na própria História, pois este é um direito do ser humano. Conhecer a própria História, a História do seu grupo, de sua comunidade, de seu gênero, de sua etnia, coloca-se como condição indispensável para se integrar com o futuro e com a vida social e política.

\footnotetext{
${ }^{2}$ A Lei Federal n 13.697, em 26 de julho de 2018, reconhece, principalmente, as mulheres que participaram do processo de Independência do Brasil na Bahia: Maria Quitéria de Jesus Medeiros, Sóror Joana Angélica de Jesus, Maria Felipa de Oliveira e João Francisco de Oliveira (João das Botas) no Livro dos Heróis e Heroínas da Pátria.
} 
Justifica-se, dessa maneira, abordar a produção do e-book e a relevância histórica de Maria Felipa, uma história que esteve fora dos livros oficiais e didáticos durante muitos anos, mas sobreviveu na cultura oral, constituindo como um patrimônio histórico cultural brasileiro e baiano. Segundo Farias (2010, p. 53):

\begin{abstract}
A Bahia é um lugar de memória identitária da ancestralidade africana e Maria Felipa de Oliveira viveu uma história singular na Ilha de Itaparica, na Independência do Brasil. A dimensão simbólica das lutas nas quais participou, criou estratégias, ironizou situações, tornou sua memória uma ressignificação do presente e proposta para contribuir na transformação do futuro.
\end{abstract}

Nos dias atuais, é importante que a história de Maria Felipa de Oliveira seja redescoberta nas escolas para que as crianças compreendam que as pessoas negras tiveram ativa e efetiva participação na construção da história do Brasil. A memória das gerações mais antigas pode ser transmitida, recontada para as próximas gerações e assim conservar essas experiências de vida e resistência que foram invisibilizadas, como a de Maria Felipa de Oliveira.

Desse modo, a prática didática amplia-se através de tecnologias educacionais, assim como a aprendizagem das crianças na reflexão étnica-racial sobre a cultura afro-brasileira, principalmente, em uma cidade com grande número de pessoas afrodescendentes como Salvador. As mídias digitais on-line permitem não apenas a pesquisa histórica por meio da leitura de textos e visualização de imagens e vídeos, como também o compartilhamento da produção escrita pelas crianças. A disposição na internet do e-book dos estudantes pode criar uma interação, com outros leitores jovens no Brasil, fomentando o debate sobre a importância da história e cultura afrodescendente na formação do povo brasileiro. Portanto, justifica-se a relevância da temática, segundo a Lei no 10.639/2003, discutida no projeto por aproximar a prática didática do sistema público de ensino das tecnologias educacionais on-line, possibilitando a reflexão sobre o papel social e transformador da educação.

\title{
O CAMINHO E A REFLEXÃO DO PROJETO
}

O projeto estabeleceu um plano de atividade para a produção e publicação on-line de e-book com os recontos da história de Maria Felipa de Oliveira, mulher negra e heroína brasileira, o qual se desenvolveu da seguinte maneira:

Inicialmente, observou-se os alunos na sala de aula e realizou-se conversas sobre o tema da tecnologia: quais recursos de tecnologia que mais utilizam, qual o acesso na escola e em casa desses recursos digitais, quais as mídias utilizadas para aprender, pesquisar as atividades escolares, se elas conheciam um e-book.

A partir dessas provocações aos alunos, o professor foi quem acabou sendo provocado com o questionamento de uma aluna: "O senhor tem canal no youtube, professor?". "Ainda não, e você tem um canal?". "Tenho", disse a aluna. Nenhum dos estudantes tinham aparelho celular, mas um dos estudantes mostrou um tablet, muito utilizado por ele para jogar games, durante intervalo das aulas. A maior parte dos alunos disseram que possuíam computadores em casa com acesso à internet, e que gostavam de ver séries e ouvir músicas on-line. Ainda não haviam escutado falar sobre e-books e gostaram da proposta de produzir um livro digital escrito por eles. Assim, apesar da escola ser numa região periférica de Salvador, onde o acesso pleno aos bens materiais ainda é uma desvantagem política e social para a população mais carente, os estudantes dessa escola já possuíam alguma relação com a tecnologia.

A seguir, os alunos e o professor pesquisaram na internet textos, imagens e vídeos sobre a história do "2 de julho, independência do Brasil na Bahia", a partir da personagem 
histórica Maria Felipa de Oliveira. A atividade dessa etapa constitui-se no registro da discussão sobre a história pesquisada e após a reescrita, através do reconto por parte dos alunos, que também ilustraram as histórias construídas.

Um dos entraves para a realização do projeto foi a ausência de uma sala de informática com computadores ligados à internet na escola para o uso pedagógico dos alunos. A sala do $4^{\circ}$ ano do ensino fundamental no dia da realização da atividade contava com 12 estudantes. Assim, para a efetivação do projeto, o professor disponibilizou seu computador pessoal, organizando a turma em três grupos com quatro alunos. Cada grupo pesquisou por 15 minutos em sites, blogs e outros canais sobre a personagem histórica Maria Felipa de Oliveira. Para manter todos atentos, improvisou-se como monitor a TV de 32 polegadas da escola, colocada em frente ao quadro. Enquanto, um grupo pesquisava, os demais alunos faziam o registro dos achados na internet sobre história de Maria Felipa na batalha do 2 de Julho. A principal questão levantada pelos alunos foi a ausência de um retrato de Maria Felipa, que era representada com diversas imagens, o professor explicou que naquele período temporal, ainda não havia câmeras fotográficas, como hoje. A partir desse envolvimento dos estudantes com a pesquisa na internet o projeto ganhou uma nova dinâmica: a representação figurativa de Maria Felipa a partir da imaginação dos estudantes.

Em outro momento, foi explicado o significado do e-book na preservação da memória histórica, sua importância como recurso digital para a aprendizagem e como o e-book pode ser compartilhado on-line na internet para que outras crianças possam ler. A seguir, os alunos pesquisaram a plataforma on-line LivrosDigitais.org, na qual são escritos, editados e publicados e-books de forma gratuita. Após o diálogo com os alunos sobre os e-books, propôs-se a realização, através da mediação do professor, de um e-book sobre a história Maria Felipa recontada por eles.

Os alunos antes do projeto não conheciam o e-book, o professor então explicou se tratar de um livro digital e apresentou alguns dos principais elementos da estrutura de um livro, seja físico, seja digital: a capa, folha de rosto, dedicatória, sumário e o texto. Logo após, retomou-se as anotações das pesquisas sobre Maria Felipa da aula anterior, lançado o seguinte questionamento aos estudantes: Como seria a luta de Maria Felipa de Oliveira em favor do povo brasileiro, de sua comunidade, de seu gênero, de sua etnia? A partir dessa provocação é que o tema do livro foi desenvolvido para instigar a reflexão e imaginação dos estudantes sobre como seria a presença histórica da personagem Maria Felipa de Oliveira, mulher negra e heroína brasileira, no século XXI.

Recontar a história de Maria Felipa de Oliveira possibilitou às crianças narrarem, criando uma teia de conexões que vincula uma geração mais antiga com a geração mais nova, evitando o perigo do esquecimento. A esse respeito, em sua palestra intitulada "O perigo da história única", a escritora nigeriana Chimamanda Ngozi Adichie (2009) argumenta: As histórias também podem ser usadas para dar poder e para humanizar. As histórias podem quebrar a dignidade de um povo. Mas as histórias também podem reparar essa dignidade quebrada.

Desse modo, a produção do e-book, na plataforma on-line LivrosDigitais.org, buscou que as crianças constituíssem laços de pertencimento com a história, como condição indispensável para se integrar com o futuro e com a vida social e política. A elaboração do ebook "\#Serlivre: Maria Felipa de Oliveira no século XXl" ocorreu de maneira colaborativa entre alunos e professor: a edição, a formatação do texto e do título. As ilustrações realizadas pelos alunos foram inseridas pelo professor, após novo debate com os alunos, participantes do processo, digitando e postando na plataforma on-line durante as aulas. 


\title{
$=$ TRAMA $=$
}

Entre algumas histórias recontadas pelos alunos, destaca-se a relação entre a história de Maria Felipa com o momento vivenciado nas escolas municipais, após uma greve de professores. Reconta um aluno em sua estória:

Era um dia uma mulher linda e muito corajosa, ela era professora, mas as greves que ela tinha que enfrentar era muitas, mas ela tinha que ser forte com as greves dos professores e ela que faz greve tentando derrubar as pessoas que só pensam em dinheiro e em mais ela lutaria e lutou até derrubar eles e assim derrubou e na felicidade eles ganharam o seu aumento o nome dela era Maria Felipa.

Entre outras histórias, a presença de ações governamentais sobre as pessoas comuns, escreveu uma aluna:

\begin{abstract}
O prefeito queria derrubar a casa de Maria Felipa ela lutou pelo direito dela, ela teve uma conversa com o prefeito, mas o prefeito ainda não tinha concordado com ela mas Maria Felipa foi na justiça e o prefeito não derrubou a casa dela.
\end{abstract}

A história de Maria Felipa de Oliveira suscitou temas fundamentais que precisam ser trabalhadas nas escolas como o bullying, o racismo e o gênero. Escreveu outra aluna:

Maria Felipa nos dias de hoje lutaria contra o racismo, defendendo os negros, iria lutar contra o bullying e contra a violência e iria mudar as escolas e o trabalho para melhor. Ela seria a primeira presidente negra e ela mudaria tudo, o racismo, violência, bullying e etc. Essa seria Maria Felipa nos dias de hoje.

O passado dos afrodescendentes, representado na história de Maria Felipa de Oliveira, está sempre inacabado, à espera de ser redescoberto, por cada criança. As narrativas recontadas pelos alunos revelaram o extraordinário: a imortalidade dos sentidos da existência humana nas histórias orais, como a de Maria Felipa, que preservou as experiências daquela geração. Ao compartilhar essa memória comum, através do e-book, as histórias das crianças dão uma nova presença ao legado do patrimônio histórico e cultural de Maria Felipa de Oliveira.

Ao final do projeto, o livro "\#Serlivre: Maria Felipa de Oliveira no século XXI" da turma foi compartilhado pelas redes sociais, com o link da página do livro no Facebook e Instagram, documentando todo o processo de produção do e-book. Os alunos também receberam uma cópia do livro em CD com capa ilustrada por eles e uma sessão de autógrafos, pois ainda nem todos possuem acesso à internet.

\section{CONSIDERAÇÕES FINAIS}

A inserção das mídias on-line na educação pode promover a reflexão sobre o mundo compartilhado entre as crianças, os jovens e o professor. Na medida em que o mundo digital em que as crianças se inserem cotidianamente também é o mundo do professor, a prática pedagógica deve promover práticas que dialoguem com os recursos tecnológicos, para juntos criarem um novo olhar sobre o mundo, que reflita sobre as histórias de resistência da cultura.

A intervenção didática apresentada no presente artigo demonstra que o enlace entre a educação e a produção de uma mídia digital na escola favorece a construção da identidade cultural afro-brasileira no ensino fundamental. A produção do e-book colocou os alunos e o professor em contato com outras linguagens, com a literatura, a arte visual, os vídeos, a internet e as redes sociais, desde o momento em que pesquisaram sobre a história de Maria Felipa de 
Oliveira, e durante a produção do reconto da história, edição, ilustração e publicação do ebook.

Portanto, a história de Maria Felipa, ao ser apropriada de uma forma pessoal pelos alunos, favorece pensar sobre sua identidade no mundo e suas relações com os eventos históricos do passado. Pesquisando, narrando e compartilhando on-line a produção com outros alunos e leitores na internet, através da plataforma digital LivrosDigitais.org, a história de Maria Felipa de Oliveira foi ressignificada no presente pelos alunos e pelo professor. Com a publicação do e-book, tem-se um novo recurso para manter a memória da herança cultural dos afrodescendentes, presente na história de Maria Felipa de Oliveira.

\section{REFERÊNCIAS}

ADICHIE, C. N. O perigo de uma história única. 2009. Disponível em:

$<$ https://www.ted.com/talks/chimamanda_adichie_the_danger_of_a_single_story/transcript?language=pt\#t1110073 >. Acesso em: 24 jan. 2018.

BRASIL. Lei de diretrizes e bases da educação nacional. (LDB). Brasilia: Senado Federal. Coordenação de Edições Técnicas, 2017.

BRASIL. Ministério da Educação. Secretaria da Educação Continuada, Alfabetização e Diversidade.

Orientações e Ações para a Educação das Relações Étnico-Raciais. Brasilia: SECAD, 2006. Disponível em: <http://portal.mec.gov.br/dmdocuments/orientacoes_etnicoraciais.pdf> Acesso: 02 abr. 2018.

DEMO, P. Educação hoje: "novas" tecnologias, pressões e oportunidades. São Paulo, SP: Atlas, 2009.

FARIAS, E. K. V. Maria Felipa de Oliveira. Heroína da Independência da Bahia. Salvador: Editora Quartetto, 2010.

FONSECA, A. G. M. F. Aprendizagem, mobilidade e convergência: mobile learning com celulares e smartphones. Revista Eletrônica do Programa de Pós-Graduação em Mídia e Cotidiano, UFF, Rio de Janeiro, n. 2, p. 163-181, junho 2013.

FREIRE, P. A educação é um ato político. Cadernos de Ciência, Brasilia, n. 24, p.21-22, jul./ago./set. 1991. Link: < http://www.acervo.paulofreire.org:8080/jspui/handle/7891/1357 >. Acesso: 30 nov. 2017.

LEMOS, A. Livro e mídia digital. Disponível em: < http:// andrelemos.info/2011/10/flica/ >. Acesso em: 01 ago. 2018.

LÉVY, P. O que é virtual. São Paulo: Editora 34, 1996.

LÉVY, P. Cibercultura. São Paulo: Editora 34, 1999.

PALFREY, J. G.; GASSER, U. Nascidos na era digital: entendendo a primeira geração de nativos digitais. Porto Alegre: Artmed, 2011.

PROCÓPIO, E. O livro na era digital: o mercado editorial e as mídias digitais. São Paulo: Giz Editorial, 2010. MACHADO, V.; PETROVICH, C. llê lfé. O Sonho do laô Afonjá (Mitos Afro-brasileiros). $2^{\circ}$ ed. Salvador: EDUFBA, 2002.

NICOLAU, M.; NICOLAU, R. Educação digital na cibercultura: para onde (não) nos leva a tecnologia. In: Temática. Ano X, n. 01 - jan/2014. Disponível em:

<http://www.insite.pro.br/2014/Janeiro/educacao_digital_cibercultura.pdf>. Acessado em: 01 ago. 2018. NICOLAU, M. Educação e novas tecnologias da informação e da comunicação: o livro didático digital no Brasil. In: Temática. Ano X, n. 07 - Julho/2014a Disponível em: <

http://periodicos.ufpb.br/ojs2/index.php/tematica >. Acesso em: 01 de ago. 2018.

PEREIRA, M.; Berleze, B. S. O racismo nas redes sociais: o preconceito real assumido na vida virtual. Anais do $4^{\circ}$ Congresso Internacional de Direito e Contemporaneidade: mídias e direitos da sociedade em rede, 2017.

ROCHA, T. B. Pesquisa em redes sociais na internet: os discursos no ciberespaço. Educação em foco (JUIZ DE FORA), v. 23, p. 225-244, 2018.

SERRES, M. Polegarzinha. Rio de Janeiro: Bertrand Brasil, 2013.

VALLETTA, D. Gui@ de Aplicativos para Educação Básica: uma investigação associada ao uso de tablets. In: Encontro Nacional de Didática e Prática de Ensino da ENDIPE, XVII, 2014, Fortaleza/CE. Fortaleza: ENDIPE, 2014.

VYGOTSKY, L. S. A formação social da mente. São Paulo: Martins Fontes, 2001. 